\title{
Considerações sobre a sexualidade dos idosos nos textos gerontológicos
}

\section{Considerations about elderly sexuality in gerontologic texts}

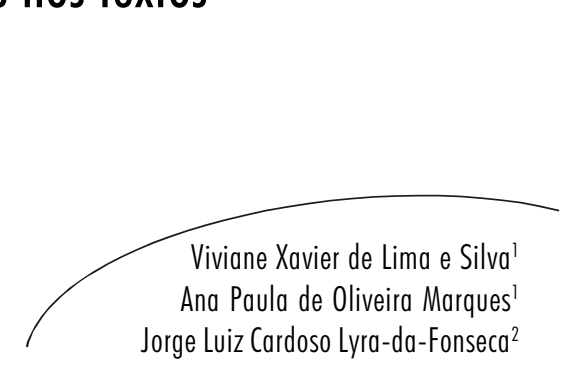

Resumo

Tanto a velhice, quanto a idéia de ciclo de vida, e também o saber gerontogeriátrico são histórica e socialmente construídos. Quando pretende afirmar cientificamente a melhor forma de viver em idade avançada, este campo de conhecimento pode tornar-se uma instância reguladora do social. A associação entre manutenção da atividade sexual na velhice e qualidade de vida é encontrada em vários textos geronto-geriátricos. Apesar de reconhecerem os complexos aspectos biopsicossociais da sexualidade, esses textos, de uma maneira geral, propõem intervenções individuais sobre as pessoas idosas e não mudanças sociais, caracterizando um lócus de reprivatização do envelhecimento. Defendemos que tanto a produção acadêmica, quanto as intervenções propostas, possam ser pautadas no respeito ao pluralismo que a sexualidade encerra e que os gerontólogos e geriatras contribuam, individual e coletivamente, para propor mudanças em padrões culturais opressores.

\footnotetext{
Universidade Federal de Pernambuco, Centro de Ciências da Saúde, Departamento de Medicina Social, Pós-Graduação em Saúde Coletiva, Recife, PE, Brasil.

2 Instituto Papai, Organização da Sociedade Civil. Recife, PE, Brasil.

Correspondência / Correspondence

Viviane Xavier de Lima e Silva

Unidade de Saúde da Família Amaury de Medeiros

Rua Roraima, s/n, UR-07 / Várzea

50960-120 - Recife, PE, Brasil.

E-mail: doc_vivi@yahoo.com.br
}

Palavras-chave:

Geriatria.

Gerontologia.

Sexualidade. Idoso.

Envelhecimento.

Comportamento

Sexual. Qualidade

de Vida. Fatores

Culturais. Precon-

ceito 


\section{Abstract}

Old age, as the idea of life cycle, and the gerontological-geriatric knowledge are historically and socially built. While aiming to confirm scientifically the best way to live in old age, this field of study can become a regulatory social instance. There is association between sexual activity in old age and quality of life in many gerontological-geriatric texts. Although those texts recognize the complex bio-psycho-social aspects of sexuality, they recommend individual interventions on elderly people and no social changes, characterizing a locus of reprivatization of aging. In our viewpoint, both academic production as the recommended interventions should be guided by respect to the pluralism

\section{Key words:}

Geriatrics. Sexuality. Aged. Aging. Sexual Behavior. Quality of Life. Cultural Factors. Prejudice. of sexuality, and that geriatric health care providers contribute, individually and collectively, to suggest changes in opressive cultural standards.

\section{INTRODUÇÃO}

O envelhecimento populacional é atualmente um fenômeno observado mundialmente. Desde 1950, a esperança de vida ao nascer aumentou 19 anos em todo o mundo e as pessoas com idade equivalente ou superior a 60 anos representam aproximadamente $10 \%$ da população do planeta. ${ }^{1}$ Viver mais sempre foi objetivo da humanidade, mas com as alterações funcionais decorrentes do envelhecimento biológico, o grande desafio passou a ser viver bem os anos de vida ganhos. ${ }^{2}$ Segundo a Organização Mundial da Saúde, o envelhecimento ativo pode ser entendido como processo de otimização das oportunidades de saúde, segurança e participação, com o objetivo de melhorar a qualidade de vida à medida que as pessoas ficam mais velhas. ${ }^{3}$

A associação entre manutenção da atividade sexual na velhice e qualidade de vida é encontrada em vários textos geronto-geriátricos. ${ }^{4-7}$ De uma forma geral, os textos que provêm de fontes ligadas ao saber biomédico (geriatras, ginecologistas, urologistas e alguns outros campos profissionais mais vinculados à assistência ao doente) tendem a focalizar os aspectos biológicos da sexualidade. Portanto, as abordagens que ganham destaque se referem às disfunções da sexualidade, em especial, a síndrome do climatério, para as mulheres, e a disfunção erétil, para os homens. Já os textos que provêm da chamada Gerontologia Social, ${ }^{8}$ habitualmente produzidos por cientistas sociais do envelhecimento (antropólogos, sociólogos e psicólogos sociais), tendem a encarar tanto a sexualidade como a velhice como construções sócio-históricas, ainda que admitam níveis diversos de construção social. ${ }^{?}$

É importante salientar que estes eixos norteadores guardam correlações com as concepções e posicionamentos políticos dos grupos sociais dos quais esses autores fazem parte. ${ }^{10}$ Assim, a militância e a produção acadêmica andam juntas nos movimentos da sexualidade, incluindo a sexualidade dos velhos. ${ }^{11}$ 
Os autores deste trabalho, apesar de suas formações acadêmicas diversificadas, identificam-se prioritariamente com os cientistas sociais do envelhecimento por entenderem que a velhice, a gerontologia e a sexualidade são construções sócio-históricas da espécie humana a partir da observação dos fenômenos biológicos que a envolvem. Por conta disso, ressaltam que mudanças nestas concepções são possíveis, como forma de construir um mundo mais justo e feliz.

\section{A VELHICE COMO EXPERIÊNCIA HETEROGÊNEA}

Nas sociedades modernas ocidentais, os ciclos de vida, definidos por faixas etárias, têm papel central na definição do curso da vida humana. Tornou-se tão natural entender este curso de vida através da sequência infância, adolescência, vida adulta e velhice, que se tem a impressão de um universalismo inerente a todos os seres humanos, como se sempre tivesse sido assim, em todas as culturas. ${ }^{8}$

É notório que os corpos de todos os seres humanos apresentam modificações com o passar dos anos, mas o significado que estas mudanças adquirem é específico de cada formação social e momento histórico. Logo, a velhice, os períodos da vida que a antecedem e a própria ideia de ciclo de vida são socialmente construídos.

A partir do momento em que se criam categorias para um determinado construto, é possível estabelecer uma hierarquia entre elas. Assim como para a escala hierárquica que avalia os atos sexuais, ${ }^{10}$ no momento em que são criados ciclos etários para descrever a experiência humana, podem-se valorizar alguns em detrimento de outros, dependendo da conformação ideológica e política vigente na sociedade em questão. ${ }^{12}$

A sociedade ocidental moderna está baseada no capital, na produção e no consumo, ${ }^{12,13}$ para a qual a juventude é um valor central; consequentemente, o lugar social destinado ao velho tem valor negativo. Se considerarmos a importância que o corpo tem neste contexto, observamos mais um lócus que reforça essa desvalorização dos velhos. O corpo de mais idade é quase invariavelmente associado à doença, invalidez, decrepitude, proximidade da morte. Envelhecer passa a ser o ficar cada vez mais distante do ideal da perfeição do corpo, já que a beleza e a juventude são associadas à saúde. ${ }^{14}$ Em especial para as mulheres idosas, pode acontecer uma relação contraditória: uma invisibilidade, na medida em que vão deixando de ser consideradas mulheres e, ao mesmo tempo, a hipervisibilidade do corpo, mas de um corpo inadequado, através do enorme estímulo ao consumo de produtos e serviços destinados a retardar a ação do tempo. ${ }^{15}$

A atenção para estas questões é particularmente importante dentro da cultura do individualismo que permeia a sociedade ocidental moderna. ${ }^{12}$ A crescente imputação dos próprios velhos pelo seu bem-estar, que tem sido chamada de reprivatização da velhice, ${ }^{12}$ acaba por gerar a ideia de 
que se o envelhecimento apresenta percalços, é por incompetência dos próprios indivíduos em manejá-lo e não se reconhece a parcela de responsabilidade do Estado e da sociedade nesta questão.

No entanto, outro risco do universalismo é encarar a velhice como uma experiência homogeneamente negativa, ignorando as experiências agradáveis que são vivenciadas por alguns grupos. A velhice também pode ser "um período de recuperar perdas, de alcançar novas conquistas e de se buscar o prazer e a satisfação pessoais."13

As diferenças de classe social e etnicidade entre os idosos e idosas também abrem espaço para vivências diversificadas na velhice. Os estudos que analisam a situação dos mais velhos em minorias étnicas ou em classes sociais empobrecidas não têm resultados concordantes. ${ }^{16}$ Ora demonstram desvantagens, a chamada dupla vulnerabilidade, ora apresentam situações privilegiadas, quando se mede o nível de interação e satisfação social.

Para Attias-Donfut, as desigualdades de gênero tendem a se acentuar entre os mais velhos. Neste início de século, a sobrevida das mulheres é maior que a dos homens na maioria dos países. Apesar disso, as mulheres adoecem mais, têm menor renda, ficam mais sozinhas e enfrentam uma desvantagem no campo simbólico "da identidade pessoal associada à imagem corporal". ${ }^{15}$ Entretanto, a experiência da velhice também pode representar um período em que as mulheres realizam novas atividades centradas na própria satisfação e no lazer. Em contextos de subordinação feminina a partir da regulação de sua capacidade reprodutiva, na velhice (ou na viuvez) a mulher pode alcançar posições mais públicas e livres, assemelhando-se às dos homens. ${ }^{17}$

\section{GERONTOLOGIA: A CIÊNCIA DA VELHICE}

Em paralelo à construção sócio-histórica da velhice, surge um campo de conhecimento para estudá-la: a Gerontologia. Apesar dos primeiros escritos científicos sobre o envelhecimento datarem do século XIX, o maior interesse pelo tema e a consequente produção científica surgem em meados do século $\mathrm{XX}$. Os trabalhos pioneiros sobre envelhecimento que embasam as práticas modernas sobre a velhice surgiram na França, através de Bichat e Charcot, porém a Geriatria aparece como especialidade médica apenas no século XX. ${ }^{18}$ Portanto, o saber geriátrico surge de demandas da sociedade, ${ }^{11}$ sendo também histórica e socialmente construído.

A Gerontologia ainda não constitui um campo articulado de saber. A maior parte da literatura especializada em envelhecimento não possui uma linguagem comum, exceto por seu objeto de estudo, ${ }^{11,19}$ A dificuldade em delimitar o que representa a idade, onde começa a velhice e as fronteiras entre o normal e o patológico representam obstáculos frente à delimitação desta área de conhecimento. ${ }^{18}$

Prado \& Sayd ${ }^{19}$ afirmam que a literatura gerontológica atribui isso ao fato de o cam- 
po estar numa fase inicial. Com o passar do tempo e o trabalho dos pesquisadores, ele tenderia a se consolidar. As autoras citadas discordam desse posicionamento, pois acreditam que a ciência não se desenvolve apenas pelo trabalho dos pesquisadores. Como proposta, utilizam o modelo de análise de Isabelle Stengers que trata de ciências e poderes, quando esta trata sobre as relações que os campos de saber que surgem estabelecem entre si e com os campos de saber já existentes consolidados e afirma que "o desenvolvimento de um conceito e o despertar de interesses em diferentes setores da sociedade, articulados a um projeto políti$\mathrm{co}$, constituem os pilares fundamentais para seu estabelecimento". ${ }^{19}$

Considerando estas questões, a Gerontologia desenvolveu formas de explicar como se dá o ajustamento do indivíduo ao seu processo de envelhecimento. $\mathrm{Na}$ teoria do desengajamento ou desvinculação, formulada no início da década de 1960 do século $\mathrm{XX}$, a pessoa realiza seu ajustamento mediante afastamento voluntário e gradual das atividades habituais, num desinvestimento, gradual e bilateral entre o indivíduo e o meio que o cerca. Já para a teoria da atividade, descrita alguns anos depois, o ajustamento é realizado por meio de práticas que compensem a inatividade, considerando importante que a pessoa se mantenha ativa e com vínculos com o meio que a cerca pelo maior tempo possível. ${ }^{20}$

Até o final da década de 1960, essas teorias foram as principais formas de se pensar o ajustamento do indivíduo à velhice no campo da Gerontologia social. ${ }^{16}$ Desde então, a teoria da atividade se tornou hegemônica, em consequência do progresso médico-científico. ${ }^{20}$ Apesar de fazerem proposições diferentes, ambas encaram a velhice como período de perdas, o que justificaria uma regulação da terceira idade e as intervenções propostas em decorrência, em nome do envelhecimento bem-sucedido.

Sob este aspecto, a Gerontologia se torna uma instância reguladora do social, na medida em que pretende afirmar cientificamente a melhor forma de viver em idade avançada. ${ }^{11}$ Groissman ${ }^{18}$ chega a afirmar que "lutando por um envelhecimento bem-sucedido, a geriatria/gerontologia parece delinear o seu mais ambicioso projeto, que é disciplinar a vida humana em toda a sua extensão"

\section{A GERONTOLOGIA E A SEXUALIDADE}

$\mathrm{Na}$ visão de Rubin, ${ }^{10}$ " uma teoria radical do sexo deve identificar, descrever, explicar e denunciar a injustiça erótica e a opressão sexual'. Ou seja, possuir instrumentos conceituais que permitam a identificação dessas situações, relatá-las de forma mais detalhada possível, teorizar sobre o que foi descrito e se posicionar politicamente.

No campo da sexualidade, a Gerontologia não se distancia de seu caráter regulador, pois pode fornecer modos de regulação tanto dos corpos individuais, quanto dos comportamentos da população. ${ }^{21}$

Vance $^{9}$ ressalta o aumento do interesse das ciências médicas pela vida sexual e como 
a abordagem biomédica da sexualidade tende a medicalizá-la e patologizá-la. Como este saber considera a sexualidade como derivada da fisiologia, tende a não refletir sobre a construção das categorias corpo e saúde. Para alguns autores, o conhecimento gerontológico sobre a sexualidade é herdeiro da sexologia, no seu cunho prático e intervencionista. ${ }^{11}$ Desde o seu início, a sexologia tem-se baseado num essencialismo sexual focado na biologia e isso tem sido questionado pela escola do contrucionismo social, inclusive o lugar central de onde vemos a sexualidade. ${ }^{21}$ Essa forma de ver a sexualidade, por entendê-la como uma construção humana, traz em si a possibilidade de transformação das desigualdades por meio da "ação intencional e de iniciativas políticas progressistas". 22

No início do século XX, Nasher, no primeiro tratado de geriatria conhecido, afırmava que alterações corporais internas e externas tinham repercussões no comportamento das pessoas idosas, dando como exemplo patológico a manutenção do interesse sexual, pois o natural seria o afastamento da vida sexual pelos indivíduos. ${ }^{18}$ Ao longo do século, os textos gerontológicos vêm-se posicionando contrariamente a $\mathrm{Na}$ sher. Um dos consensos atuais do saber gerontológico é que a sociedade, por discriminar os velhos de forma geral, condena sua sexualidade e que esse controle sobre seus atos seria exercido pelos jovens, mas também pelos próprios velhos. ${ }^{11}$ Este conceito é descrito nos textos como o mito da velhice assexuada.
Pode-se afirmar que as sociedades modernas ocidentais avaliam os atos sexuais segundo uma escala hierárquica. Quanto mais baixa a posição da prática sexual na escala, mais seus praticantes perdem socialmente em respeitabilidade, mobilidade, legalidade, amparo institucional, benefícios materiais e status de saúde mental. ${ }^{10}$ É perfeitamente possível encarar o controle sobre a sexualidade dos velhos desta maneira. As normas culturais (estereótipo que liga velhice à decrepitude) são introjetadas e se traduzem nas condutas individuais, incluindo as da sexualidade. ${ }^{13,23}$

Os especialistas, baseados na noção de direitos da velhice, posicionam-se contrariamente a este ponto de vista, ${ }^{24}$ muitas vezes baseados em Freud e suas observações da sexualidade com finalidade de prazer, em detrimento da reprodução. ${ }^{23}$ Esse argumento é frequentemente a justificativa para suas intervenções. Mauro Brigeiro ${ }^{11}$ cita Thomas como uma das vozes discordantes que associa, através de uma interessante metáfora, a sexualidade os velhos ao prazer e não como estratégia de sobrevivência, para a manutenção da qualidade de vida. Ele defende que a experiência sexual na terceira idade não seja encarada como vitaminas (consumidas por motivo de saúde) e sim como a pipoca, um alimento sem muito valor nutritivo, associado aos momentos de lazer.

Aqui se corre mais um risco de homogeneização de uma experiência múltipla. Sendo assumida como verdade que a velhice não é assexuada, tampouco todos os ve- 
lhos mantêm interesse sexual nesta etapa da vida. Para os que vivenciam sua sexualidade, também não existe obrigação de esta ser experimentada de forma única. Esta reflexão é importante para evitar que se migre da velhice assexuada para a obrigação de desempenho sexual, especialmente como necessário à manutenção da saúde, nem para a normatividade das sexualidades culturalmente hegemônicas.

Os autores construtivistas admitem níveis diferentes de construção social (atos, identidades, comunidades, a direção do interesse erótico e até o próprio desejo), apesar de compartilharem a ideia de que as experiências sexuais têm significados diversos, dependendo do contexto em que se inserem. ${ }^{9}$ Mesmo não havendo consenso, esses estudos pensam a sexualidade como construção social. Portanto, para analisar qualquer prática vinculada à sexualidade, é fundamental perceber os sentidos que ela tenha para o sujeito que a exerce, dentro de seu momento histórico e contexto cultural.

Frequentemente, a intervenção gerontológica objetiva otimizar o exercício da sexualidade entre os idosos, dentre as suas limitações nas várias dimensões da vida. A velhice instauraria uma nova concepção de sexualidade, como algo mais amplo que o coito penetrativo. ${ }^{11}$ Ainda assim, este conhecimento geronto-sexológico se utiliza muito mais de dados empíricos de frequência sexual e dos conceitos de fisiologia sexual, ${ }^{4,7,25}$ não encarando, efetivamente, a sexualidade de forma ampliada. Este fato pode ser consequência da chamada ausência de um conceito de variedade sexual benigna. Se há um conceito comum de que há uma forma de fazer sexo melhor do que as outras e que todos deveriam se esforçar para fazê-lo apenas desta maneira, dificilmente irá se desenvolver uma ética sexual pluralista. ${ }^{10}$ Assim, os indivíduos resistiriam a essa possibilidade de mudança em sua sexualidade, reforçando a ideia de perda provocada pela velhice. Isto também explicaria a ausência quase completa de menção a práticas sexuais não-hegemônicas, como as homoeróticas, nos textos gerontológicos sobre a sexualidade.

Apesar de se reconhecer os complexos aspectos "biopsicossociais" (expressão recorrente em vários textos gerontológicos) da sexualidade após os 60 anos, de maneira geral, propõem-se intervenções individuais para os idosos e não mudanças sociais, caracterizando mais um lócus de reprivatização do envelhecimento.

\section{CONSIDERAÇÕES FINAIS}

Gayle Rubin ${ }^{10}$ afirma ainda que a sexualidade é política porque está organizada em sistemas de poder que recompensam a alguns e punem outros e, por isso, é objeto de luta desde que se desenvolveu nesses sistemas. A autora defende que uma prática sexual deveria ser julgada "pela forma como se tratam seus participantes, pelo nível de consideração mútua, pela presença ou ausência de coerção e pela quantidade e quali- 
dade de prazeres que aporta", e não por uma moral da sexualidade única e homogênea. ${ }^{10}$

Neste contexto, como ciência militante, assumimos o posicionamento político a favor da liberdade dos indivíduos para manter ou não a atividade sexual após os 60 anos, com qualquer significado que esta possa ter para eles, independentemen-

\section{REFERÊNCIAS}

1. Pereira RS, Curioni CC, Veras, RP. Perfil demográfico da população idosa no Brasil e no Rio de Janeiro em 2002. Textos sobre envelhecimento. 2003; 1: 43-59.

2. Garrido R, Menezes PR. O Brasil está envelhecendo: boas e más notícias por uma perspectiva epidemiológica. Rev Bras Psiquiatr 2002; 24 Supl I:S3-6.

3. World Health Organization. Envelhecimento ativo: uma política de saúde. Brasília: Organização PanAmericana de Saúde; 2005.

4. Penteado SRL, Fonseca AM, Bagnoli VR, Assis JS, Pinotti JA. Avaliação da capacidade orgástica em mulheres na pósmenopausa. Rev Assoc Med Brás 2004; 4: 444-50.

5. Vaz RA, Nodin N. A importância do exercício físico nos anos maduros da sexualidade. Análise Psicológica 2005; 23 : 329-339.

6. Ribeiro JP, Santos A. Estudo exploratório da relação entre função eréctil, disfunção eréctil e qualidade de vida em homens portugueses saudáveis. Análise Psicológica 2005; 23: 341-9.

7. De Lorenzi DRS, Saciloto B. Frequência da atividade sexual em mulheres te dos padrões culturais construídos. Defendemos que tanto a produção acadêmica, quanto as intervenções propostas, possam ser pautadas no respeito ao pluralismo que a sexualidade encerra e que os gerontólogos e geriatras contribuam, individual e coletivamente, para propor mudanças em padrões culturais sexualmente opressores.

menopausadas. Rev Assoc Med Brás 2006; 4: 256-60.

8. Prado SD. O curso da vida, o envelhecimento humano e o futuro. Textos Envelhecimento. 2002; 8 .

9. Vance CS. A Antropologia redescobre a sexualidade. Physis 1995; 1: 7-31.

10. Rubin G. Thinking sex: notes for a radical theory of the politics of sexuality. In: Vance CS, organizador. Pleasure and danger: exploring female sexuality. Londres: Routledge and Kegan Paul; 1984. p. 267-319.

11. Brigeiro M. Envelhecimento bemsucedido e sexualidade - relativizando uma problemática. In: Barbosa RM, Aquino EML, Heilborn ML, Berquó E. Interfaces - gênero, sexualidade e saúde reprodutiva. Campinas: Unicamp; 2002. p. 171-206.

12. Barros MML. Velhice na contemporaneidade. In: Peixoto CE, organizador. Família e envelhecimento. Rio de Janeiro: FGV; 2004. p. 13-24.

13. Ramos RBA. O desejo não tem idade: a sexualidade da mulher idosa. Recife: Fasa; 2002. 
14. Mori ME, Coelho VLD. Mulheres de corpo e alma: aspectos biopsicossociais da meia-idade feminina. Psicologia: Reflexão e Crítica 2004; 2: 177-87.

15. Attias-Donfut C. Sexo e envelhecimento. In: Peixoto CE , organizador. Família e envelhecimento. Rio de Janeiro: FGV; 2004. p. 85-108.

16. Debert GG. A reinvenção da velhice: socialização e processos de reprivatização do envelhecimento. São Paulo: Edusp; 2004.

17. Motta AB. Sociabilidades possíveis: idosos e tempo geracional. In: Peixoto CE, organizador. Família e envelhecimento. Rio de Janeiro: FGV; 2004. p. 109-44.

18. Groisman D. A velhice, entre o normal e o patológico. História, Ciências, Saúde. 2002 jan./abr; 1:61-78.

19. Prado SD, Sayd JD. A gerontologia como campo do conhecimento científico: conceito, interesses e projeto político. Ciência \& Saúde Coletiva. 2006; 2: 491-501.

20. Oliveira RCS. Velhice: teorias, conceitos e preconceitos. A Terceira Idade. 2002; 25 : 36-51.

Recebido: $21 / 2 / 2008$

Revisado: $16 / 10 / 2008$

Aprovado: 30/3/2009
21. Weeks J. O corpo e a sexualidade. In: Louro GL, organizador. O corpo educado: pedagogias da sexualidade. Belo Horizonte: Autêntica; 2001. p. 37-82.

22. Parker R. Cultura, economia política e construção social da sexualidade. In: Louro GL, organizador. O corpo educado: pedagogias da sexualidade. Belo Horizonte: Autêntica; 2001. p. 12749.

23. Vasconcellos D, Novo RF, Castro OP, Vion-Dury K, Ruschel A, Couto MC, et al. A sexualidade no processo do envelhecimento: novas perspectivas - comparação transcultural. Estudos de Psicologia 2004; 3 : 413-9.

24. Risman A. Corpo-psique-sexualidade: uma expressão eterna. In: Veras RP. Terceira idade - alternativas para uma sociedade em transição. Rio de Janeiro: RelumeDumará; 1999. p. 161-72.

25. Lopes G, Torres LO, Maia MB. Sexualidade e envelhecimento normal. In: Cançado FAX. Noções práticas de Geriatria. Belo Horizonte: Coopmed; 1994. p. 402-11. 
